Final Report: Hierarchical Coupled Modeling and Prediction of Regional Climate Change in the Atlantic Sector

\author{
R. Saravanan, Ping Chang, and Guy Almes \\ Texas A\&M University
}

Funding Period: 8/1/2007 - 7/31/2011

\title{
I. Summary of results
}

During the course of this project, we have accomplished the following:

a) Carried out studies of climate changes in the past using a hierarchy of intermediate coupled models (Chang et al., 2008; Wan et al 2009; Wen et al., 2010a,b)

b) Completed the development of a Coupled Regional Climate Model (CRCM; Patricola et al., 2011a,b)

c) Carried out studies testing hypotheses testing the origin of systematic errors in the CRCM (Patricola et al., 2011a,b)

d) Carried out studies of the impact of air-sea interaction on hurricanes, in the context of barrier layer interactions (Balaguru et al)

\section{a) Hierarchical modeling of past climate change:}

We used an ocean-atmosphere general circulation model to examine the link between oceanographic changes in the North Atlantic Ocean and changes in the strength of the African monsoon (Chang et al., 2008). Our simulations show that when North Atlantic thermohaline circulation is substantially weakened, the flow of the subsurface North Brazil Current reverses. This leads to decreased upper tropical ocean stratification and warmer sea surface temperatures in the equatorial South Atlantic Ocean, and consequently reduces African summer monsoonal winds and rainfall over West Africa. This mechanism is in agreement with reconstructions of past climate. Our results suggest that the interaction between thermohaline circulation in the North Atlantic Ocean and wind-driven currents in the tropical Atlantic Ocean contributes to the rapidity of African monsoon transitions during abrupt climate change events.

A conundrum exists regarding whether the sea-surface temperatures (SST) decreased or increased over the southern Caribbean and the western Tropical Atlantic region during the Younger Dryas when the North Atlantic cooled substantially and the Atlantic thermohaline circulation was weakened significantly. Despite the proximity of core locations, some proxy reconstructions record a surface cooling, while others indicate a warming. Our studies (Wan et al., 2009) using an intermediate coupled ocean-atmosphere 
model suggest that this seemingly paradoxical finding may, at least partially, be attributed to the competing physical processes that result in opposing signs of temperature change in the region in response to weakened North Atlantic meridional overturning circulation. Our numerical experiments indicate that the temperature response over the southern Caribbean and Western Tropical Atlantic regions is complex and can vary considerably in small spatial scales, depending on the nature of physical processes that dominate.

Previous coupled climate model simulations reveal that a dipole-like SST pattern with cooler (warmer) temperature over the north (south) tropical Atlantic emerges in response to a slowdown of the Atlantic meridional overturning circulation (AMOC). We used two model configurations, (i) a 26-layer reduced gravity ocean model (RGOM) and (ii) an intermediate coupled model, where an atmospheric general circulation model (AGCM) is coupled to the RGOM. Using the RGOM, we investigated the oceanic processes controlling the tropical Atlantic SST response to AMOC changes by varying the strength of northward mass transport at the open boundaries was conducted (Wen et al., 2010a). We found that the North Brazil Current (NBC) reverses its direction in response to a shutdown of the AMOC. Such a circulation change causes a decrease in upper equatorial ocean stratification and warming in the Gulf of Guinea and off the coast of Africa. These findings point to the importance of oceanic dynamics in the equatorial SST response to AMOC changes. Further experiments using the intermediate coupled model (Wen et al., $2010 \mathrm{~b}$ ) reveal the relative importance of oceanic processes and atmospheric processes in AMOC-induced tropical Atlantic variability. It is found that the oceanic processes are a primary factor contributing to the warming at and south of the equator and the precipitation increase over the Gulf of Guinea, while atmospheric processes are responsible for the surface cooling of the tropical North Atlantic and southward displacement of ITCZ.

b) Development of a Coupled Regional Climate Model (CRCM): The primary goal of our project was the development of the CRCM. The final configuration of the CRCM is comprised of the WRF and ROMS models implementing the Mercator projection and the Arakawa $\mathrm{C}$ grid for horizontal discretization (Fig. 1). Taking advantage of this commonality, we have implemented a hierarchy of common spatial grids for both models, currently at $27 \mathrm{~km}$ and $9 \mathrm{~km}$ resolutions, and in the future extending down to $3 \mathrm{~km}$. This obviates the need for interpolation when using the same horizontal resolution. The two models exchange fluxes of momentum heat, and freshwater every 6 hours when coupled.

Our original plan was to couple the atmospheric and oceanic models at the same horizontal resolution. Our preliminary analysis of integrations of the $27 \mathrm{~km}$ WRF coupled to the $27 \mathrm{~km}$ ROMS model indicated the ocean model was relatively inexpensive computationally, when compared to the atmospheric model. Furthermore, eddy-resolving resolution in the ocean was essential to properly simulate the Gulf Stream separation (Fig. 2). To address these two issues simultaneously, we decided to increase the standard resolution of the ocean model from $27 \mathrm{~km}$ to $9 \mathrm{~km}$, while keeping the atmospheric model resolution at $27 \mathrm{~km}$. This means that there are 9 ocean grid boxes corresponding to each 
atmospheric grid box. During air-sea flux exchange, SST is averaged over the oceanic grid boxes and the atmospheric fluxes of heat, freshwater and momentum into the ocean are simply distributed uniformly over the finer grid. (In coastal regions, we assume that the coarser grid box is a land grid box if it contains fewer than 5 oceanic grid boxes.)

Increasing the ocean model resolution not only allowed us to obtain a better simulation of the Gulf Stream separation, but also resulted in a better load balance, with WRF using 384 processors and ROMS using 288 processors on a typical integration on the Ranger supercomputer at the University of Texas. In addition to the standard $27+9$ configuration for the CRCM, we have also configured a fine-resolution $9+9$ version of the CRCM, by increasing the atmospheric model resolution to $9 \mathrm{~km}$ while keeping the ocean model resolution the same. In this case, both models use the same horizontal grid, and no interpolation of surface fluxes is necessary.

Currently the $27+9$ version of the CRCM is suitable for production runs, and the $9+9$ fine-resolution version is suitable for shorter sensitivity runs. The control integration of the $27+9$ version of the CRCM is able to simulate hurricane activity in the tropical Atlantic (Figs. 3,4) in addition to providing a better simulation of the Gulf Stream separation. We have carried out analyses of the surface biases and hurricane-ocean interaction in the CRCM and companion uncoupled integrations, as described below.

c) The origin of systematic errors in CRCM simulations: Like most climate models, the CRCM integration exhibit biases in its climate simulation. Of particular interest is the climate bias in the tropical Atlantic simulations, which is pervasive amongst global coupled general circulation models (CGCMs). We have investigated the tropical Atlantic bias problem using CRCM, with the $27+9 \mathrm{WRF}+\mathrm{ROMS}$ configuration (Patricola et al., 2011a,b).

Uncoupled atmospheric simulations using WRF were used to test climate sensitivity to cumulus, land-surface, planetary boundary layer, microphysics, and radiation parameterizations. This revealed that the radiation scheme has a pronounced impact in the tropical Atlantic. The CAM radiation simulates a dry precipitation (up to $-90 \%$ ) and cold land-surface temperature (up to $-8 \mathrm{~K}$ ) bias over the Amazon related to an overrepresentation of low-level clouds and almost basin-wide westerly trade wind bias. The Rapid Radiative Transfer Model and Goddard radiation simulates doubled Amazon and Congo Basin precipitation rates and a weak eastern Atlantic trade wind bias. Season-long high-resolution CRCM integrations indicate that the initiation of the warm eastern equatorial Atlantic SST bias is more sensitive to the local rather than basin-wide trade wind bias and to a wet Congo Basin instead of dry Amazon - which differs from CGCM simulations. Comparisons between coupled and uncoupled simulations suggest a regional Bjerknes feedback confined to the eastern equatorial Atlantic amplifies the initial SST, wind, and deepened thermocline bias, while barrier layer feedbacks are relatively unimportant. The SST bias in some CRCM simulations resembles the typical CGCM bias indicating that increasing resolution is unlikely a simple solution to this problem. 


\section{d) Hurricane-ocean interaction in the CRCM:}

One of the advantages of the high-resolution CRCM model is that it can simulate finescale phenomena like tropical cyclones better than global coupled general circulation models. We have carried out a series of integrations using the CRCM to study the impact of fine-scale air-sea interaction on track and intensity of tropical cyclone, focusing in particular on Atlantic hurricanes.

Normally, the passage of a hurricane leaves behind a cold wake in the ocean, with enhanced vertical mixing caused by the hurricane resulting in cold SST anomalies as the colder subsurface water is mixed with the warmer surface waters. However, there are certain regions in the tropical Atlantic, especially in the Caribbean, where anomalously warm subsurface temperatures can be found in the ocean. These oceanic "temperature inversions" occur in conjunction with a phenomenon known as the oceanic "barrier layer", which is present when the depth of the isothermal layer exceeds the depth of the mixed layer. The portion of the isothermal layer below the mixed layer acts as a barrier to mixing, and hence the name. When a hurricane passes over a region where a barrier layer is present, it can actually lead to warmer SST in the wake of the hurricane, as the warmer subsurface waters are mixed with the surface waters. This warming could potentially affect the intensity of the hurricane, resulting in a positive feedback.

Our analysis of hurricane-ocean interaction in the CRCM integrations shows examples of both the normal behavior, i.e. surface cooling associated with the passage of a hurricane, as well as the abnormal behavior, i.e., surface warming resulting from the passage of the hurricane (Fig. 5). Overall, our results suggest that the intensification rate for hurricanes can be significantly amplified by the presence of a barrier layer. A manuscript summarizing these results is in preparation for publication (Balaguru et al.)

\section{Presentations and publications/manuscripts describing work wholly or partially} supported by this project

\section{a) Presentations}

Saravanan, R., P. Chang, and G. Almes, 2007: Hierarchical Coupled Regional Climate Modeling in the Atlantic Sector. Poster presentation at the Climate Change Prediction Program Meeting, Indianapolis, IN, September 2007.

Saravanan, R., 2007: A Multiscale Approach to Modeling Climate Change in the Mississippi River Basin. Oral Presentation at the China-US Research Round Table on Linking Global Climate Variability and Change to Coastal Ecosystem Change: A Comparative Study of the Yangtze and Mississippi River Basins. Washington, DC, October 2007

Saravanan, R., J. S. Hsieh, P. Chang, H. Seidel, and G. Creager, 2008: Hierarchical Coupled Modeling in the Atlantic Sector. Poster Presentation at the $13^{\text {th }}$ Annual CCSM Workshop, Breckenridge, CO, June 2008. 
Saravanan, R., J. S. Hsieh, P. Chang, H. Seidel, and G. Creager, 2008: Hierarchical Coupled Regional Climate Modeling in the Atlantic Sector. Oral Presentation at the American Geophysical Union, Fall Meeting, San Francisco, CA, December 2008.

Saravanan, R., J. S. Hsieh, P. Chang, H. Seidel, and G. Creager, 2009: Development of a highresolution coupled regional climate model in the Atlantic sector for climate change studies. Oral Presentation at the $21^{\text {st }}$ Conference on Climate Variability and Change, American Meteorological Society, Phoenix, AZ, January 2009.

Hsieh, J.S., C. Wen, P. Chang, and R. Saravanan, 2009: Modeling Atlantic tropical instability waves using a coupled regional climate model. Oral Presentation at the 16th Conference on Air-Sea Interaction, American Meteorological Society, Phoenix, AZ, January 2009.

Saravanan, R., J. S. Hsieh, M.K. Li, P. Chang, H. Seidel, and G. Creager, 2009: Hierarchical Coupled Modeling and Prediction of Regional Climate Change in the Atlantic Sector. Poster Presentation at the Climate Change Prediction Program Meeting, Bethesda, MD, April 2009.

Karthik Balaguru, 2009: Role of Upper Ocean Stratification in Hurricane-Induced Vertical Mixing and Implications for Meridional Heat Transport in the Ocean. Conference on OceanAtmosphere Energy Transport, California Institute of Technology, November 2009

Hsieh, Jenshan., Mingkui Li, R. Saravanan, and Ping Chang, 2009: Downscaling Tropical Cyclone Activity using a Coupled Regional Model: Impact of Air-Sea Coupling on Atlantic "Hurricane" Simulations". Oral Presentation at the American Geophysical Union, Fall Meeting, San Francisco, CA, December 2009.

R. Saravanan, 2010: Hurricanes and Air-Sea Interaction in the Tropical Atlantic. Tropical Atlantic and PIRATA-15 meeting, Miami, FL, March 2010

Karthik Balaguru, 2010: Barrier layers in the Atlantic warmpool - Formation and influence on climate at various time-scales. Tropical Atlantic and PIRATA-15 meeting, Miami, FL, March 2010

Saravanan, R., J. S. Hsieh, M.K. Li, P. Chang, G. Creager, and G. Almes, 2010: Coupled Regional Climate Modeling in the Atlantic Sector. Poster Presentation at the DOE Integrated Climate Change Modeling Science Team Meeting, Gaithersburg, MD, March 2010.

Chang, P., R. Saravanan, M. Li, J.-S. Hsieh, C. M. Patricola, and K. Balaguru: A Study of Meso and Frontal Scale Air-Sea Interactions Using a High-Resolution Atlantic Regional Coupled Model. European Geosciences Union, General Assembly, Vienna, April 2011

Saravanan, R., P. Chang, J.-S. Hsieh, C. Patricola: High-Resolution Coupled Regional Climate Modeling: Applications to the Atlantic Sector. Guanajuato Water Conference, Mexico, May 2011

\section{b) Publications/manuscripts}

Chang, P., Zhang, R., Hazeleger, W., Wen, C., Wan, X., Ji, L., Haarsma, R. J., Breugem, W.-P. and Seidel, H. 2008: An Oceanic Teleconnection Between Abrupt Changes in High-Latitude North Atlantic Climate and the African Monsoon. Nature Geoscience, 1,444-1,448. doi:10.1038/ngeo218

Wan, X., P. Chang, R. Saravanan, R. Zhang, and M. W. Schmidt, 2009: On the interpretation of Caribbean paleo-temperature reconstructions during the Younger Dryas. Geophys. Res. Lett., 36, L02701, doi:10.1029/2008GL035805. 
Wen, C., Chang, P., and Saravanan, R., 2010a: Effect of Atlantic Meridional Overturning Circulation Changes on Tropical Atlantic Sea-Surface Temperature Variability: A 2-1/2 layer Reduced Gravity Ocean Model Study. Journal of Climate, 23, 312-332.

Wen, C., Chang, P., and Saravanan, R., 2010b: Effect of Atlantic Meridional Overturning Circulation Changes on Tropical Atlantic Sea-Surface Temperature Variability: A Regional Coupled Model Study. Journal of Climate, v.24, pp. 3323-3343.

Patricola, C.M., P. Chang, R. Saravanan, M. Li, and J.-S. Hsieh, 2011a: An investigation of the Tropical Atlantic bias problem using a high-resolution coupled regional climate model. US CLIVAR Variations, Vol. 9, No. 2, 8-12pp.

Patricola, C.M., M. Li, Z. Xu, P. Chang, R. Saravanan, and J.-S. Hsieh, 2011b: An investigation of tropical Atlantic bias in a high-resolution coupled regional climate model. Climate Dynamics, In Press

Karthik Balaguru, P. Chang, R. Saravanan, 2011: Barrier layers in the Atlantic warmpool Formation and influence on climate at various time-scales. Manuscript in preparation.

\section{Figures}

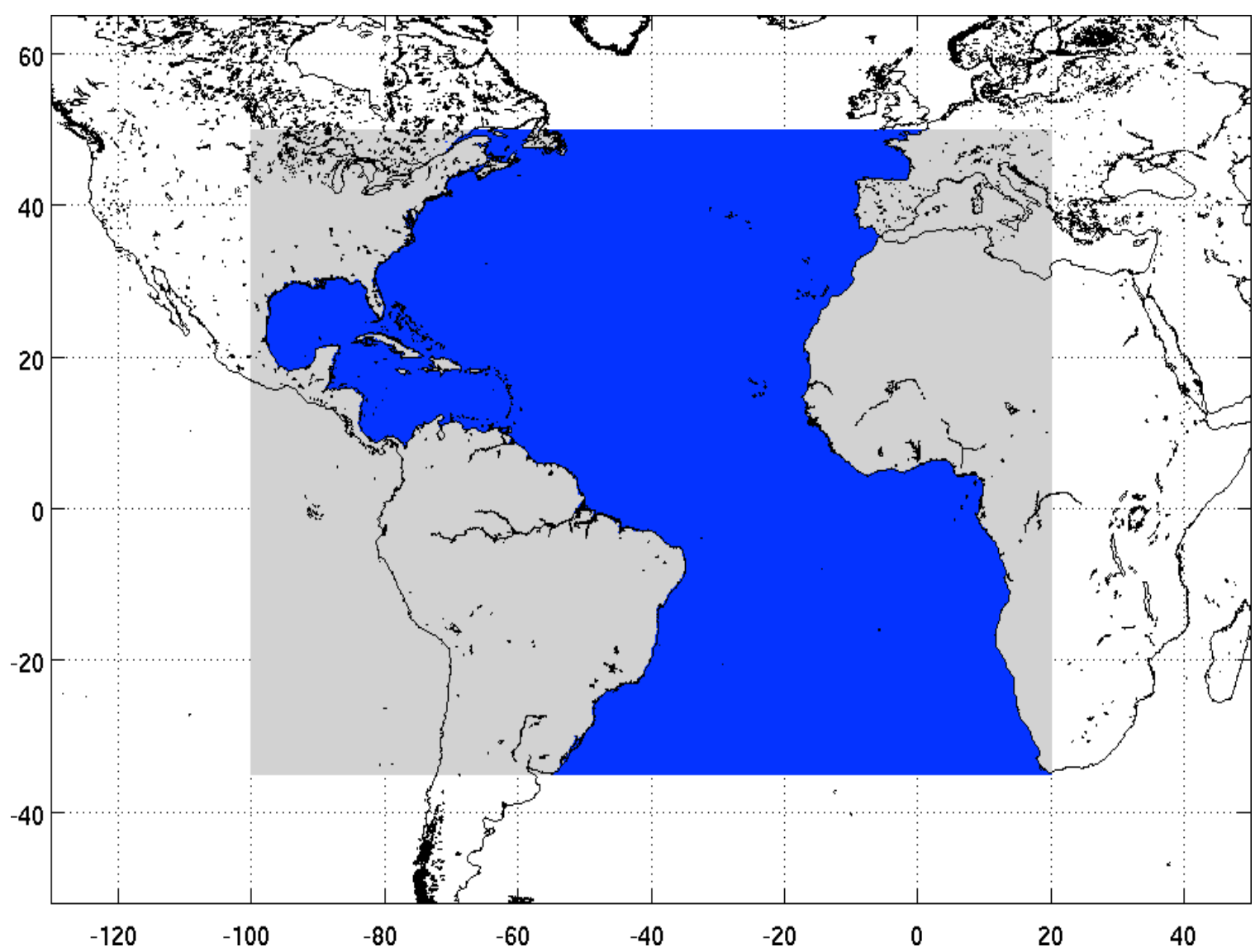

Figure 1: Coupled Regional Climate Model (CRCM) domain. Blue indicates ocean model domain. Gray/blue indicates atmospheric model domain. 


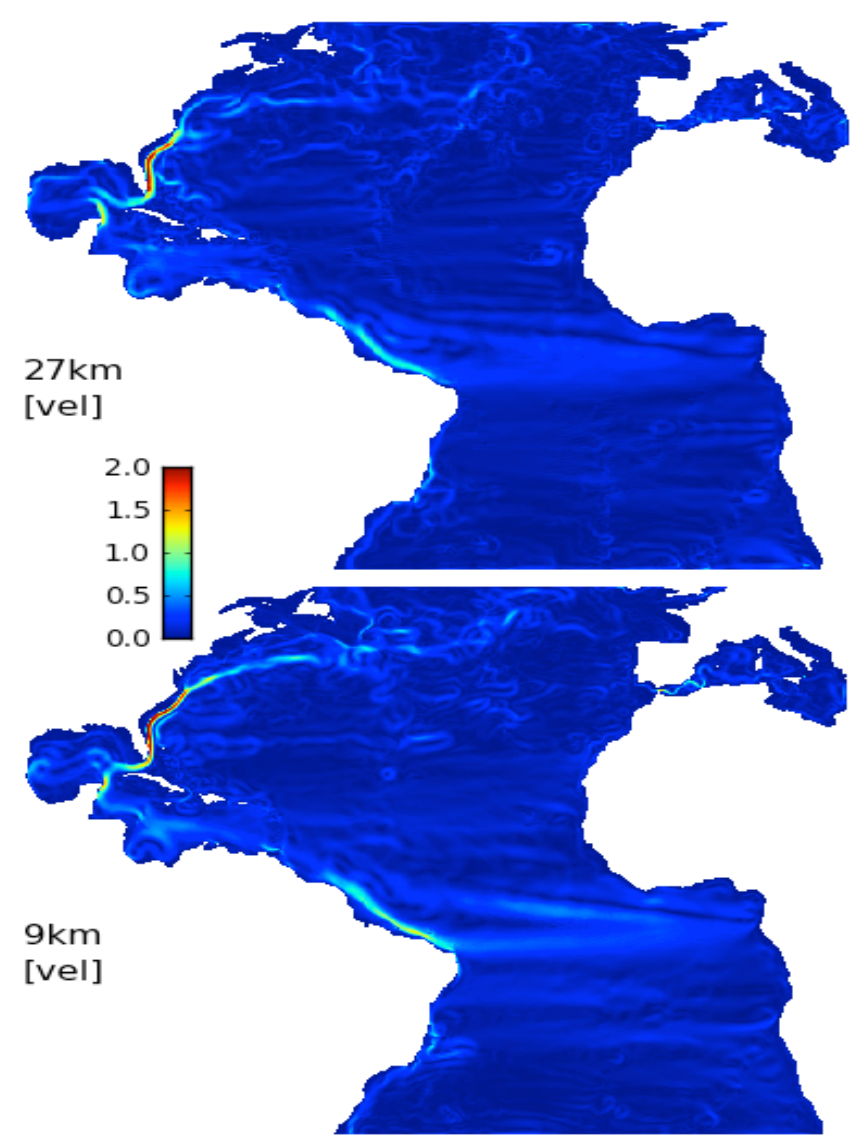

Figure 2: Surface current speed in uncoupled ROMS integrations: $27 \mathrm{~km}$ resolution (top), $9 \mathrm{~km}$ resolution (bottom). Note the better simulation of Gulf Stream separation at $9 \mathrm{~km}$ resolution. 
10m Wind / Rainfall [mm/day] - Day 05
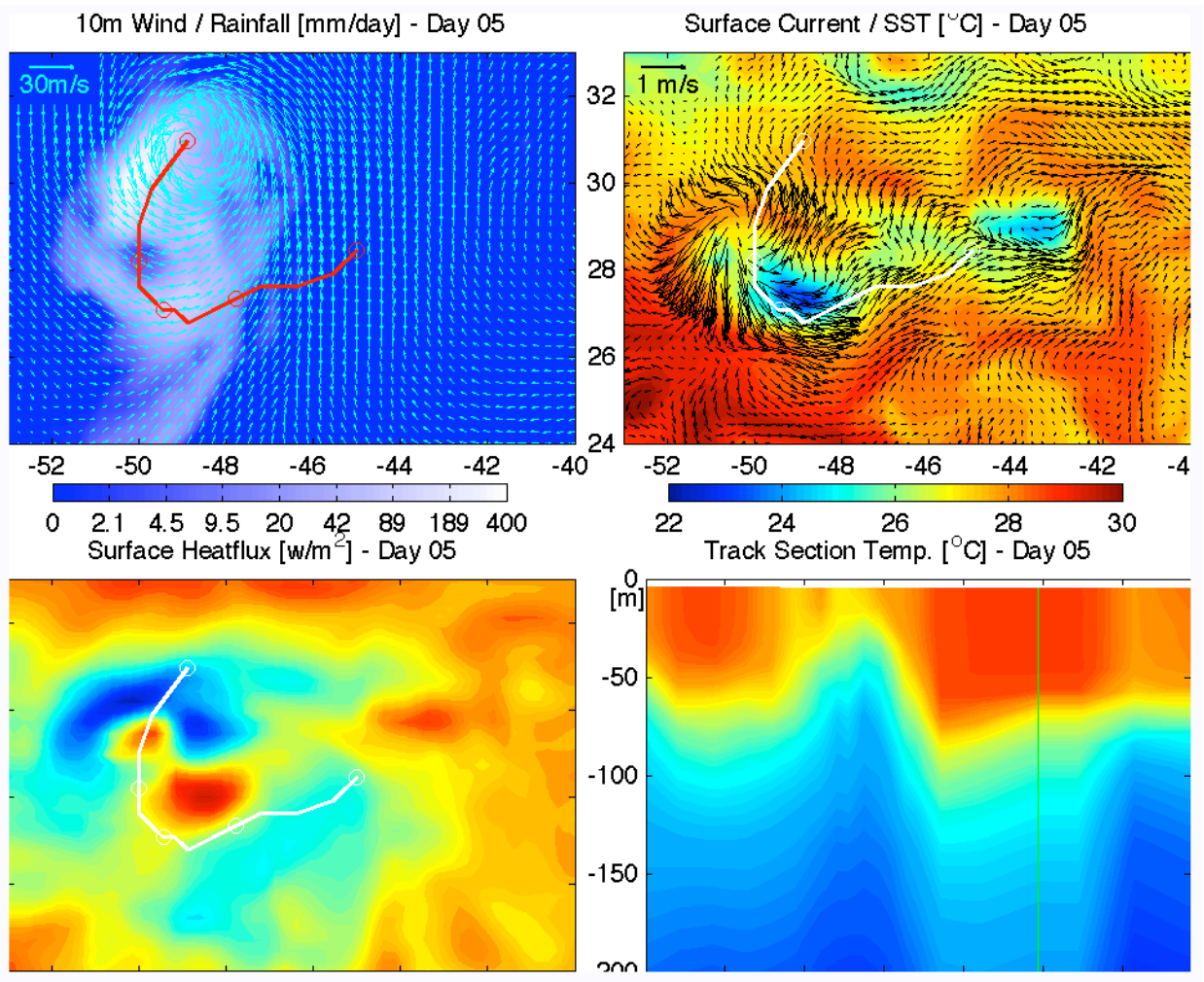

Figure 3: Hurricane simulation in the CRCM: rainfall/wind (top-left), surface current (top-right), surface heat flux (bottom-left), and along-track vertical temperature profile in the ocean (bottomright).

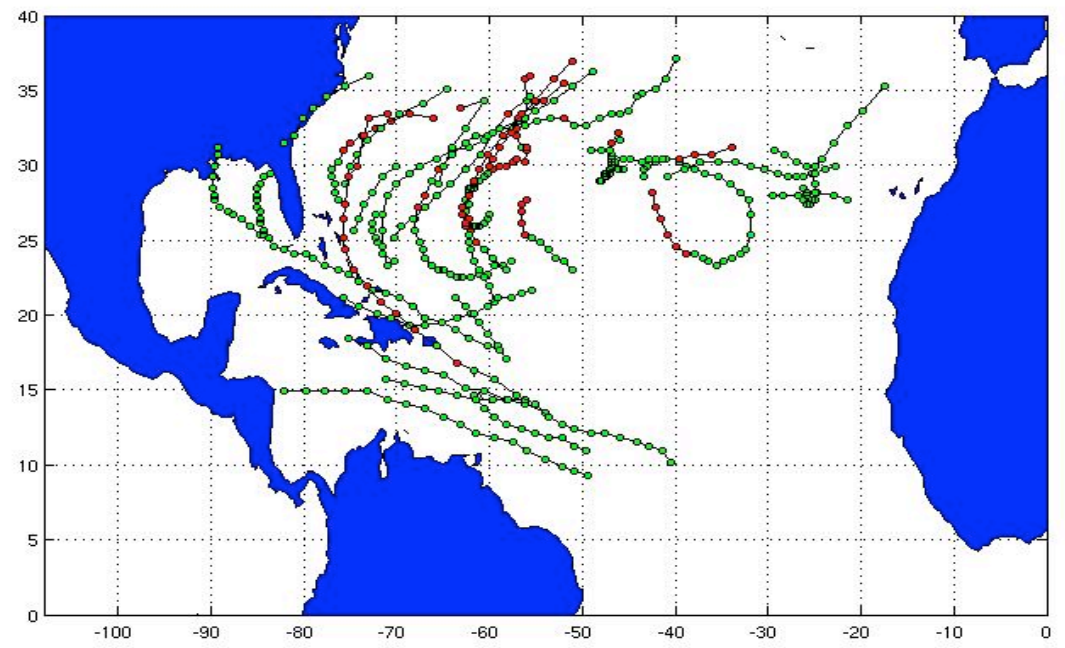

Figure 4: Tropical storm tracks during first year of control (27+9) CRCM integration 

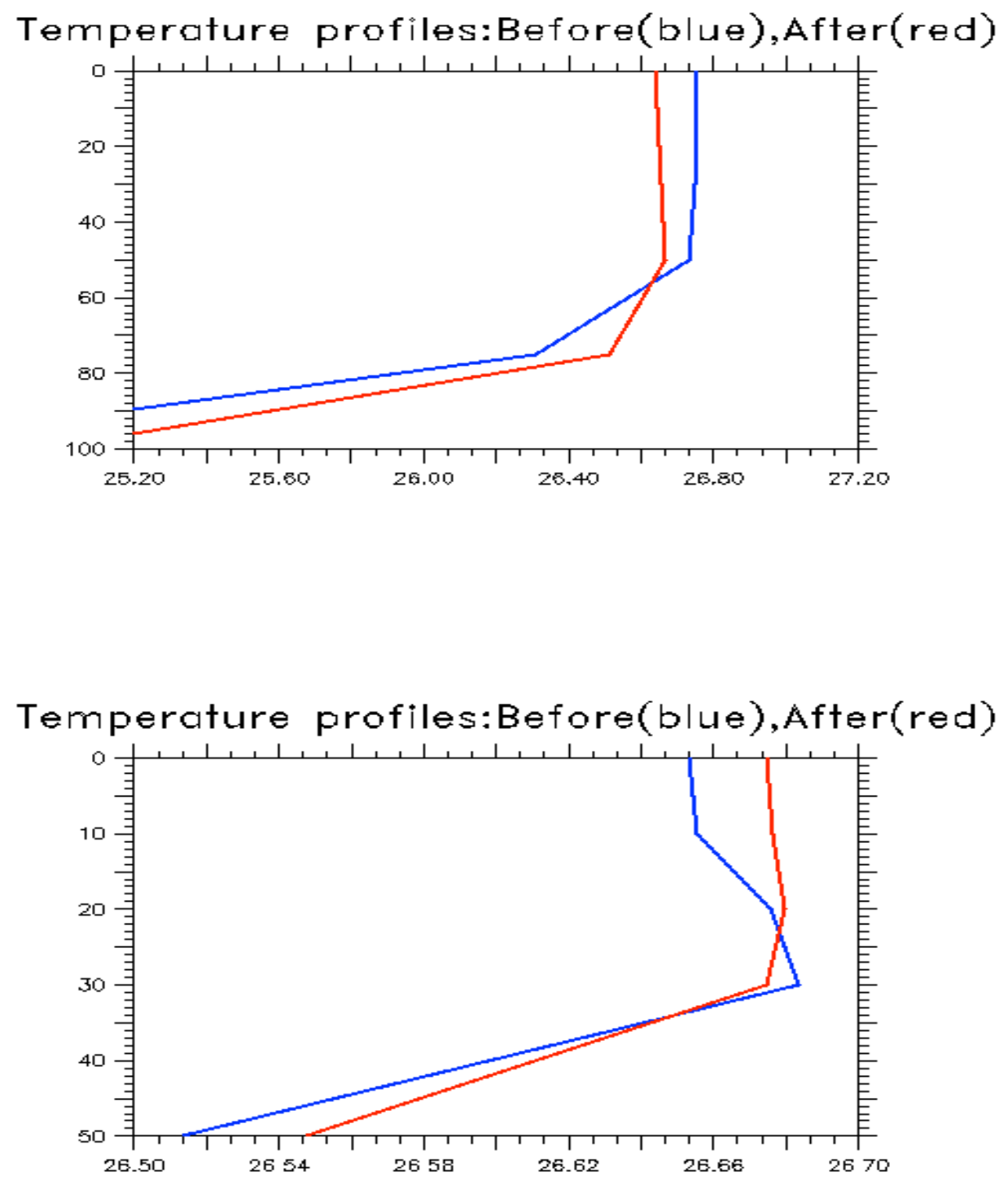

Figure 5: Hurricane-ocean interaction: vertical temperature profile in the upper ocean before (blue) and after (red) the passage of hurricane (as simulated in the control CRCM integration). Top panel shows a normal case, where the enhanced vertical mixing associated with the passage of a hurricane leads to surface cooling. Bottom panel shows the case where a simulated hurricane passes over an oceanic "barrier layer" with a temperature inversion present. The passage of the hurricane actually leads to warmer surface temperatures in this case! 